\title{
A Survey of Islamic Clergy \& Community Leaders Regarding Muslim Mental Health First Responder Training
}

\author{
Farhad Syed \\ Khalil Center Department of Psychological Research/The Chicago School of \\ Professional Psychology \\ farhadsyed@khalilcenter.com
}

\section{Sara Keshavarzi}

University of Windsor/Khalil Center Department of Psychological Research sarakeshavarzi@khalilcenter.com

\section{Naushin Sholapur}

Khalil Center Department of Psychological Research

naushin@khalilcenter.com

\section{Hooman Keshavarzi}

Khalil Center, Department of Psychological Research/Ibn Haldun University keshavarzi@khalilcenter.com

\section{Abstract}

There are significant behavioral healthcare disparities for North American Muslims including limited accessibility to mental healthcare services offered with an Islamic context. Thus, American Muslims typically turn to Islamic clergy and religious community settings to address their mental health needs prior to seeking professional care. In order to improve accessibility to Islamically oriented mental health supports, the Khalil Center, an Islamically oriented Muslim mental health center, constructed an 8-hour Muslim Mental Health First Responder Training (FRT) administered across the United States and Canada to 498 community leaders and Islamic clergy. Post-training survey data found that although most of the 128 respondents were involved in settings that necessitated responding to mental 
health issues in their communities, $70 \%$ had never received any previous mental health training. The overwhelming majority ( $80 \%$ ) of participants emphasized their appreciation of an Islamically integrated approach to the training, reporting that it changed their perceptions, attitudes, and beliefs about mental health and $92 \%$ stated they would recommend the training to other colleagues. The majority of participants $(61.7 \%)$ in the FRT were teachers, imams/scholars, and counselors. These positions in the community have a high interpersonal impact on the community and can be considered for many people, the first line of defense against mental health-related disorders. This survey illustrated the importance of addressing mental health from a faith-based perspective in the American Muslim community and the inclusion of Islamic clergy and community leaders in order to facilitate a collaborative care approach to closing the gaps of mental health needs for the American Muslim community.

The practice of integrating religion and spirituality into the field of psychology is rapidly expanding. A recent shift toward culturally sensitive and religiously attuned therapeutic techniques have demonstrated significantly improved client outcomes (Richards, Sanders, Lea, McBride, \& Allen, 2015; Worthington, Hook, Davis, \& McDaniel, 2011). However, considerable mental healthcare disparities still exist. There remains a lack of services and mental health resources that cater specifically to the needs of the growing North American Muslim population. Relatedly, the underutilization of mental health services among the North American Muslim population is concerning (Ali \& Milstein, 2012). For example, results from a survey of 179 Muslim clients conducted by Khalil Center from October 2016 to April 2018 found that 67\% of clients had reported that they had not sought mental healthcare from mainstream behavioral health care systems. However, results from the same survey also demonstrated that $95 \%$ of Khalil Center's Muslim clientele felt it was extremely or somewhat important that religion and spirituality be an essential part of the therapy process. The survey data suggests that Muslims would be more likely to seek help if spiritually integrative therapy services were available to better suit their needs.

Muslims are the largest growing minority in the United States facing religious, cultural, and ethnic discrimination in an increasingly hostile sociopolitical climate (Ali, Milstein, \& Marzuk, 2005; Nimer, 2002). There has been a significant increase in the need for counseling and support with mental health related issues following the 9/11 attacks and their fallout, and community imams are predicting continuous deterioration of mental health and wellbeing among Muslims due to discrimination and harassment (Ali, Milstein, \& Marzuk, 2005; Haque \& Kamil, 2012). Trauma is becoming of increasing concern, with Muslims reporting a high degree of posttraumatic stress disorder from 9/11-related trauma, wars in their native countries, and discrimination (Abu-Ras \& Abu Bader, 2008). Despite the imminent need, there remain many barriers to help-seeking behavior in Muslim communities such as mistrust of 
service providers and lack of understanding around confidentiality, fears of treatment and discrimination, and differences in communication relating to issues of culture and religion (Inayat, 2007).

The first contact for help among Muslims during times of psychological distress is often an imam, a clergy member, or spiritual leader from the religious community, for Islamic faith healing (Farooqi, 2006; Kianpoor \& Rhoades Jr., 2005). Seeking the counsel of an imam may be a result of Muslims typically attributing their psychological distress to metaphysical causes including demonic possession (jinn or zar) (Kianpoor \& Rhoades Jr., 2005), punishment for past sins, being cursed or evil eye through others' jealousy, or separation from the Divine (Salib \& Youakim, 2001). Unfortunately, few religious scholars have any formal training in mental health (Ali, Milstein, \& Marzuk, 2005), suggesting a need for Islamically integrative care and community collaboration. Although the presence of emerging institutions like Khalil Center in the United States of America and Canada has helped address the need for spiritually integrative mental health interventions, the demand for care far exceeds the ability of any one institution to fill the gaps.

The duties of imams inherently involve providing spiritual direction (e.g., leading prayers, delivering sermons, performing religious ceremonies, providing spiritual guidance, etc.) and maintaining the functionality of a cohesive community (Ali \& Milstein, 2012). Imams play a vital role in assisting with the distress and counseling needs of Muslims (Wang, Berglund, \& Kessler, 2003). A study by Ali, Milstein, and Marzuk (2005) on illness recognition and referral practices among American imams, found that $50 \%$ of the 62 imams surveyed spent one to five hours each week providing counseling services. The most commonly reported problems were spiritual or religious advice and relationship or marital stress. $68 \%$ of respondents noted a significant increase in counseling for issues related to fear and discrimination (Ali, Milstein, \& Marzuk, 2005). Despite the extensive pastoral counseling that imams partake in, clergy members do not commonly have knowledge pertaining to mental health-related disorders and are not often equipped with the resources to respond, particularly to potential clinical problems that reach beyond their scope of expertise (Milstein, Manierre, Susman, \& Bruce, 2008; Milstein, Manierre, \& Yali, 2010). Thus, lack of mental health knowledge and skills among imam and Islamic clergy could have adverse effects on the mental health of congregants by impeding help-seeking behaviors. This is of concern as to the degree of efficacy that imams could achieve in their treatment with the usage of spiritual counseling methods alone (Razali, 1999). Ideally, a process should exist whereby imams are able to recognize congregants who show signs and symptoms of mental illness and are able to refer them to a mental health practice that can provide them with Islamically oriented care (provided religion is central to their way of life). 
Clergy members can seek training programs devised to assist with understanding and responding to mental health, however participation is low (Ali \& Milstein, 2012). Mental Health First Aid (MHFA), developed by the Mental Health Commission of Canada; Psychological First Aid, created by the World Health Organization (WHO; 2011); and Mental Health: A Guide for Faith Leaders, by the American Psychiatric Association (APA; 2016) are some of the most widely used available training guides. Of these available manuals, the APA guide is the only one that includes a faith-based approach (APA, 2016).

There is some precedent to underscore the importance of training for clergy and community leaders. The Center for Church-Psychology Collaboration (CCPC) at Wheaton College in Illinois has incorporated a mental health component into clergy training. Research evaluating this integrative program found that relationships between clergy members and mental health professionals improve when they share religious ideals and feel respected by psychologists (McMinn, Aikins, \& Lish, 2003). While the APA has begun to address the lack of clergy consideration in training models, there remains a need for training with a focus on Muslim mental health. The objectives of collaborative training models have been to increase mental health awareness among clergy in order to help direct clients to the appropriate sources. Additionally, trainings must be offered to reduce public harm by highlighting clergy limitations and equipping them with the tools required to respond to crises and assist in treatment processes. It is important that clergy members be aware of their limitations, available resources, and crisis management skills given the mental health epidemic and the frequency with which religious individuals turn to clergy in times of distress. A major benefit of these trainings is the possibility of cutting down on cost and wait times which are often prohibitive barriers for many individuals in seeking care from mental health professionals (WHO, 2003).

While the demand for support services and clergy training regarding Muslim mental health is high, the supply of necessary resources remains low. This necessitates a collaborative care approach and clinical pastoral training with an emphasis on Muslim mental health to encourage the consultation and communication needed to cater to the growing concerns among Muslim communities (Ali \& Milstein, 2012). A collaborative approach will support all components needed for Muslims to achieve the goal of balance in all states, including the soul ( $r \mathrm{u} h)$, behavioral inclinations (nafs), emotions (ihsaas), and cognition ('aql) (Keshavarzi \& Haque, 2013). To address this need for mental healthcare education among North American Muslim clergy, the Khalil Center developed the 'Muslim Mental Health First Responder Training' (FRT) program in 2016. The FRT is a mental health first aid program specifically designed to train imams and community leaders. The purpose of the program was to equip clergy members with the tools and knowledge base necessary to identify and respond to congregants who show signs of mental health-related disorders and 
encourage a collaborative relationship between religious leaders and mental health professionals.

The FRT program is an 8-hour long workshop conducted by the Khalil Center and facilitated by mental health professionals trained in Islamically oriented models of care. The FRT is unique in providing a faith-based training, tailored to improve clergy members' understanding and responding to mental health concerns, with a focus on Muslim populations. The main objectives of this program for imams and Islamic clergy are to: 1) gain familiarity with mental health conditions; 2) understand the system of mental health referral; 3 ) understand how to empathetically listen and respond to crisis; 4) increase awareness of relational processes that influence the pastoral relationship; 5) appreciate the need to work with and collaborate with mental health professionals; and 6) recognize the parameters and limitations of pastoral care services. The training progresses through modules that equip clergy members with an introduction to an Islamically integrative model and the skills to form a counseling relationship within a pastoral care setting. The second module provides an understanding of mental illness as well as how to screen individuals and conduct mental status examinations. The third module focuses on Islamic law and clergy rights and responsibilities as they relate to mandated reporting, ethical and legal limitations, and roles as well as boundaries. Finally, the training concludes with special topics such as marital issues, youth, trauma, and substance use.

In order to determine if the program was meeting its objectives and catering to the needs of religious leaders within the Muslim community, several benchmarking processes were incorporated in an iterative process improve the program as per the needs of the community. The aim of this paper is to describe the results of a post-training survey conducted to obtain feedback from attendees from the Muslim Mental Health FRT program and describe future directions for community-oriented first aid trainings for the Muslim community.

\section{Methods}

\section{Muslim Mental Health FRT Program}

The Muslim Mental Health FRT workshops, were conducted by Khalil Center trainers. The training was co-facilitated by doctoral level licensed mental health professionals with formal Islamic studies backgrounds, and an additional Islamic clergy member from the Khalil Center. Clergy members involved in the FRT were seminary graduates, holding behavioral sciences degrees, with credentials ranging from Bachelor's to Master's level degrees. Clergy member co-facilitators for the trainings were active religious consultants working 
within an interdisciplinary community outpatient mental health setting, and therefore have exposure to and experience with mental health concerns. The varying academic and religious academic degrees in the behavioral sciences and Islamic theology were deemed critical for translational ability between the fields of study.

Through this training, the Khalil Center's mission is to educate chaplains, imams, scholars, teachers, and others who are serving the North American Muslim community. Participants are expected to have developed a number of skills including building a therapeutic alliance, empathy, and listening skills by the end of the training. Among the key aims of the training are fostering skills that teach clergy members the importance of working collaboratively, understanding their limitations and boundaries, and best practices for making referrals. A program can cost between $\$ 25.00-\$ 100.00$ per participant depending on whether the host community could subsidize the cost.

\section{Study Design and Administration of the Survey to FRT Participants}

A cross-sectional, self-report survey of teachers, imams, counselors, and other individuals who attended the Muslim Mental Health FRT between 2016 and 2018 was conducted. A convenience sample of all respondents who completed the FRT training was taken. Surveys were developed online using Google Forms and sent via email to participants after the trainings were completed. All participants who registered for the training with their email or had provided their emails during the sessions received the survey. Respondents could complete the survey at their convenience. No personal identifiers were collected for the purposes of this study and responses were anonymous.

The survey was distributed to 498 individuals across 8 training sessions (in Chicago, IL, Washington, D.C., Tempe, AZ, Hartford, CT, San Francisco, CA, East Lansing, MI, Passaic, NJ, and Toronto, Canada). The total number of responses received were 128; yielding a response rate of $25.7 \%$ (128/498). The study population were primarily comprised of teachers $(34.4 \%)$, imams/ Islamic scholars (20.3\%), and counselors (7\%) who had completed the FRT program. The remainder of study population were a combination of students, community volunteers, board members, and administrative leaders of mosques, khatîbs (people who deliver sermons), and chaplains.

The survey was reviewed by individuals conducting the FRT training in order to ensure that all questions asked were within the scope of the training. Once the survey was finalized, the team opted to use Google Forms to collect and capture the data with ease. Open-ended questions focusing on strengths, weaknesses, and improvements to the program were asked in order to obtain a comprehensive understanding of participants' views of the FRT. However, the survey primarily focused on receiving feedback about the training sessions 
and included questions about: the aspects of training that participants found most useful; the importance of having an Islamically oriented mental health training available; whether participants felt the training session improved their understanding and knowledge of mental health and illness; and, if the training changed participant's perceptions/general attitudes toward mental health and illness.

Additional questions focused on participant's prior experience, training, and knowledge related to mental health and illness (not necessarily focusing on the integration or role of spirituality within the mental health field). Participants were also asked to report whether or not they would have attended a similar training by a different organization, and if they would have attended the training had it not been informed by Islamic values.

Finally, the survey asked participants to describe their position in their community and provide an approximate number of people they serve in order to estimate the projected impact of the training on the North American Muslim community. A general comments and feedback section was also included to capture any information that the survey did not explicitly collect.

\section{Results}

Approximately $50 \%$ of FRT participants reported that they counsel or provide therapy to others on at least a weekly basis; $18.4 \%$ of the entire study population provide counseling services on a daily basis. Although the remaining 50 $\%$ of participants may not provide support through counseling/therapy very often, they are frequently in positions to provide support to their families or members of their community informally. Most respondents (53.6\%) indicated serving populations of up to 50 individuals; a minority of participants reported serving populations between $50-100$ individuals (16.8 \%) and some over 200 individuals (18.4\%). Although most respondents (61.6\%) indicated that there was no way the training could have been more geared toward their position in the community, $38.4 \%$ disagreed. Individuals who felt the workshop could have been more geared toward their position in community provided the feedback that: training could be more specific to imams (as opposed to the layperson); training on how to respond to mental health issues with specific populations such as students and trauma victims; and, counseling techniques specific to teacher-student relationships.

The data showed that nearly $70 \%$ of participants had never attended any mental health trainings previously. Of the $30 \%$ of individuals who indicated they had attended previous mental health trainings, most were not Islamically or religiously focused. Approximately $80 \%$ of participants potentially would not have attended this training if it was not designed with Islamic values (33.6 
$\%$ would definitively not attend, whereas $46.1 \%$ were undecided). These results demonstrate the strong need for a comprehensive Islamically oriented training program within the Muslim community.

Overall, the attitudes toward the FRT program were overwhelmingly positive. $92 \%$ of all respondents indicated they would recommend this training to their colleagues; $88 \%$ of respondents reported that they are interested in taking a "Level 2" of the FRT. Nearly $60 \%$ of respondents report their beliefs and perception of mental health changed as a result of this training. All of the participants felt that, after the FRT, they better understood mental illnesses and its solutions. Specifically, a majority of individuals (55.2\%) found the Islamic approach to mental health, current research available on mental health, the presenters, and the need for such a program to be appealing aspects of the training. Approximately $77.6 \%$ of respondents felt that the training was important or very important for them to have.

Respondents were asked to provide feedback about what aspects of the training could be improved for the future. Some key features included: dividing the material up into greater number of days in order to reduce the intensity of the program; including assessments to test training participants' retention of the information; and, more dedicated time to apply theoretical knowledge under the supervision of a mental health practitioner.

\section{Discussion}

The results indicate that an Islamically integrated mental health training geared toward imams and clergy leaders was, in general, well received and useful. This is likely due to the training content and focus on Islamic perspective that are consistent with clergy members' religious and pastoral training backgrounds. The training was designed to empower imams and religious clergy on how to recognize and identify mental illness, while developing an awareness of the boundaries and limitations of their own knowledge, skills, and practice. It is important that clergy members' are aware of their roles, the protective factor that religion serves, and their accompanying rights and responsibilities. The FRT training facilitated outreach between mental health professionals and religious leaders, thereby improving the likelihood of referral. Increasing a network of referral resources and consultation opportunities allows clergy members to establish practices consistent with mental health principles and formalize counseling sessions for community members when psychological issues can be ruled out. The evidence from this survey demonstrates the need for further similar training opportunities and integrative models aimed at understanding and assisting the Muslim community as well as improving relations between clergy members' and professional clinicians for optimal care outcomes. 
There is some precedent to underscore the importance of training for clergy and community leaders. The Center for Church-Psychology Collaboration (CCPC) at Wheaton College in Illinois has incorporated a mental health component into clergy training. Research evaluating this integrative program found that relationships between clergy members and mental health professionals improve when they share religious ideals and feel respected by psychologists (McMinn, Aikins, \& Lish, 2003). While the APA has begun to address the lack of clergy consideration in training models, there remains a need for training with a focus on Muslim mental health. The objectives of collaborative training models have been to increase mental health awareness among clergy in order to help direct clients to the appropriate sources. Additionally, trainings must be offered to reduce public harm by highlighting clergy limitations and equipping them with the tools required to respond to crises and assist in treatment processes. It is important that clergy members be aware of their limitations, available resources, and crisis management skills given the mental health epidemic and the frequency with which religious individuals turn to clergy in times of distress. A major benefit of these trainings is the possibility of cutting down on cost and wait times which are often prohibitive barriers for many individuals in seeking care from mental health professionals (WHO, 2003).

Community mental health clinics play an integral role in bridging the gap between North American Muslims and mental healthcare professionals. Collaboration between imams and mental health professionals is required to bridge the current gaps in mental health care, thereby ensuring the availability of an interdisciplinary approach to addressing the needs of this religious minority. While some imams report a willingness to collaborate with mental health professionals, they seldom refer or consult in practice (Ali \& Milstein, 2012). The results of this study corroborate the findings of the literature given that the majority of respondents had never had any previous mental health training in the past; moreover, training was never integrative of Islamic principles. Therefore, potential reasons for the lack of referral and communication between mental health professionals and clergy members can be attributed to a lack of awareness regarding resources and a lack of communication with mental health care providers (Ali \& Milstein, 2012). Many imams may also be unfamiliar with diagnostic categories rendering them unlikely to recognize mental illness or the system of mental health referrals (Ali \& Milstein, 2012). In order to make referrals, imams must be able to identify psychopathological symptoms and have an established network and system of referrals. Khalil Center's First Responder Training serves the dual purpose of not only raising awareness and destigmatizing mental health and illness, but also equipping community leaders who may access large congregations with the necessary tools to manage clients who require mental healthcare services.

Imams, clergy, and community leader serve a large population; in this 
study alone, the participants were estimated to serve approximately 12,000 individuals collectively. Of these, it is estimated that approximately $20 \%$ will require mental healthcare services (NIMH, 2019). Therefore, this training program is estimated to directly impact 2,400 individuals who need mental health services. While this number is a conservative estimate, individuals who have completed this training will be able to apply the skills they develop in their dayto-day interactions, sermons, and other duties. Thus, the indirect impact of this program is even more far reaching.

\section{Study Limitations}

Despite the keen interest in the FRT program, the low response rate was a limitation of the study, which may have an impact on the generalizability of the study results. One reason for the low response rate was that some surveys were sent with time lag of several weeks after the FRT was conducted, potentially introducing a recall bias. In future studies, post-training surveys should be administered shortly after the training is complete. This may lead to an increased number of participants in the survey, as well as potentially more accurate feelings toward the training as described by participants. While the survey was designed to collect occupational information, participants' demographics were not captured and impeded the research team's ability to characterize the attendees. However, since occupation, role in the community, and other details related to their professional work were captured, the impact on not collecting personal information such as age and gender was minimal.

\section{Conclusion}

This study was conducted using survey methods in order to gain a general understanding and feedback of the FRT from a wide cross-section of participants. The survey was able to identify several important strengths and weaknesses of the program. It also elucidated the various roles that individuals who enroll in the program are fulfilling which allows administrators to better tailor content to their needs. In the future, a qualitative component to allow respondents the opportunity to provide more thorough answers to the open-ended questions should be incorporated. Benchmarking exercises should be undertaken to obtain a better understanding of participant expectations and to ensure the objectives of the program are being met.

The Muslim Mental Health First Responder Training is fulfilling a growing need for clergy, chaplains, teachers and others who deal directly with the mental health of the Muslim community. This study, while small, gives insight into the current state of North American Muslim mental health care system 
and provides evidence for creating mental health resources for the MuslimAmerican community.

\section{Appendix A}

First Responder Training Survey Responses

Would you have attended this mental health training if it was not informed by Islamic values?

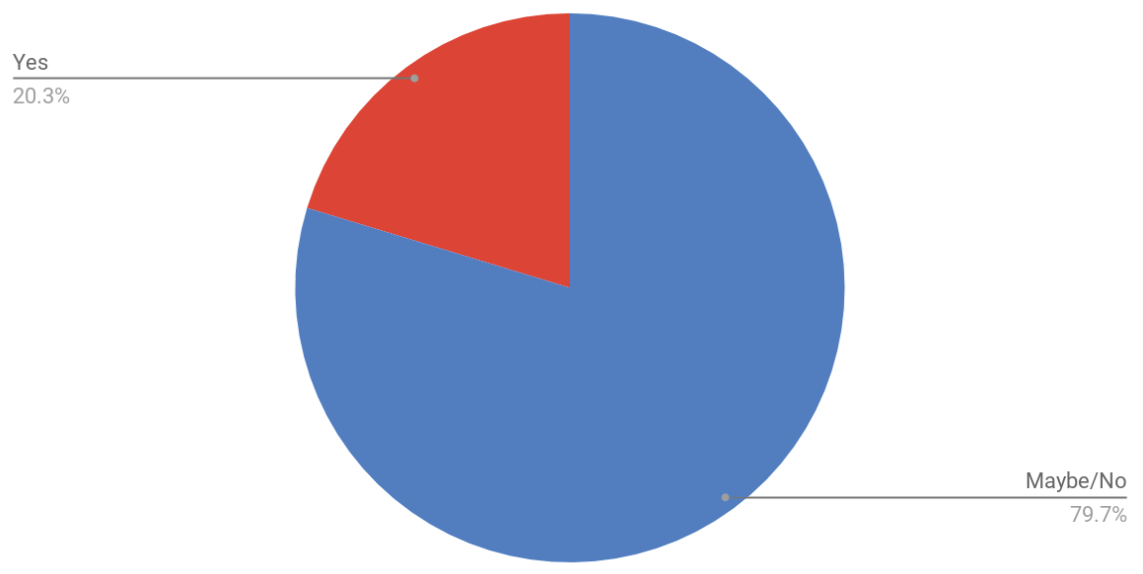

How many individuals do you serve in your community (approximately)?

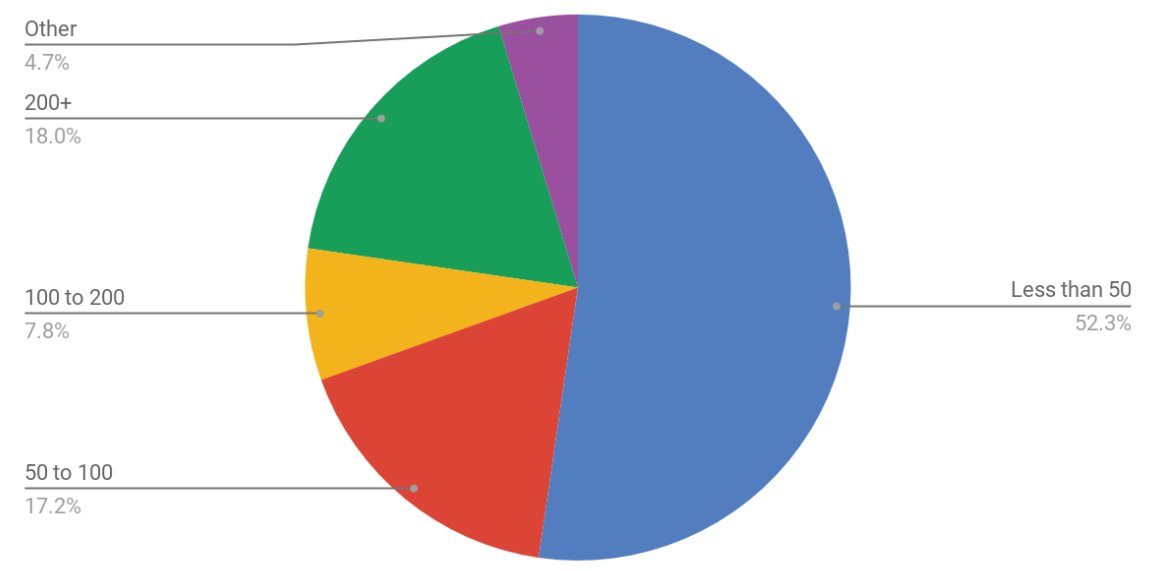


Would you recommend this training (FRT) to colleagues?

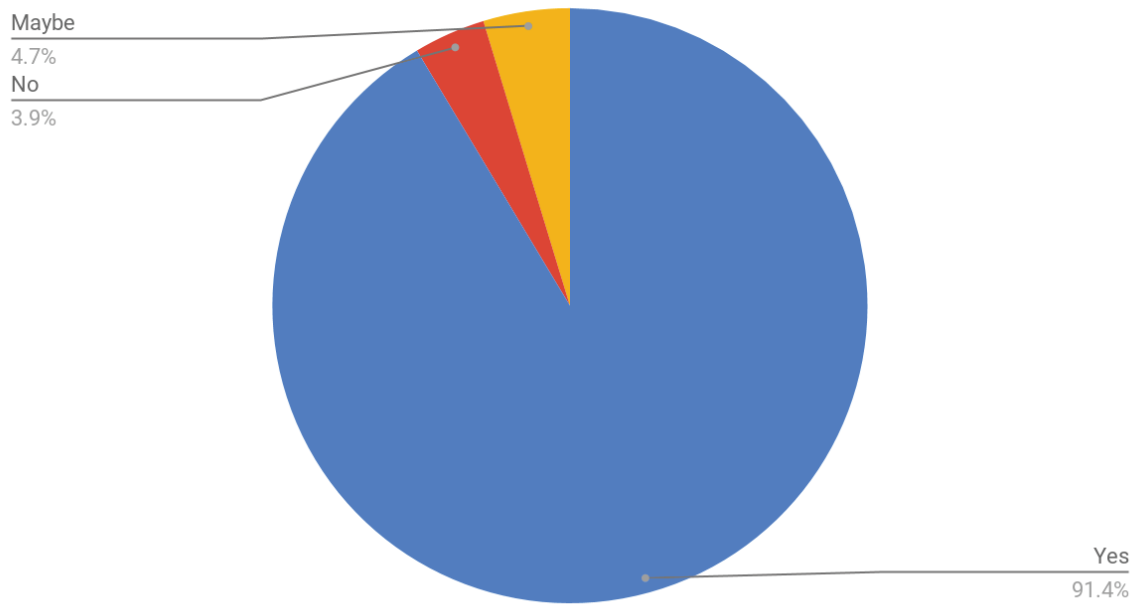

After completing the training (FRT), do you have a better understanding of mental illnesses and its solutions?

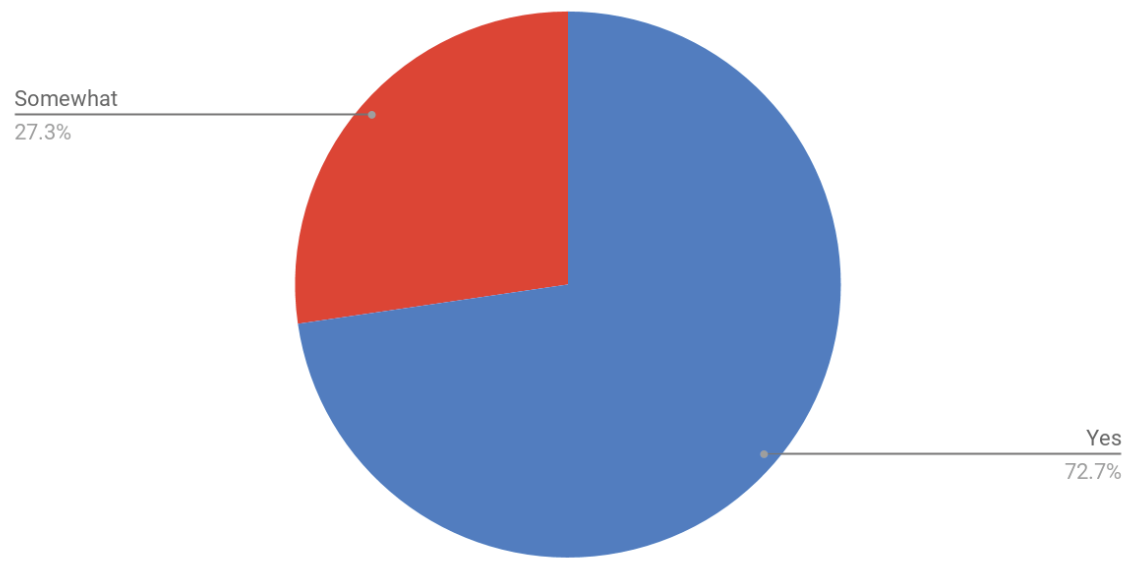




\section{References}

Abu-Ras, W., \& Abu-Bader, S. H. (2008). The impact of September 11, 2001, attacks on well-being of Arab Americans in New York City. Journal of Muslim Mental Health, 3, 217-239.

Ali, O. M., \& Milstein, G. (2012). Mental illness recognition and referral practices among imams in the United States. Journal of Muslim Mental Health, 6(2), 3-13.

Ali, O. M., Milstein, G., \& Marzuk, P. M. (2005). The imam's role in meeting the counseling needs of Muslim communities in the United States. Psychiatric Services, 56(2), 202-205.

American Psychiatric Association Foundation. (2016). Mental Health: A guide for faith leaders. Arlington, VA: APA.

Farooqi, Y. N. (2006). Traditional healing practices sought by Muslim psychiatric patients in Lahore, Pakistan. International Journal of Disability, Development and Education, 53, 401-415.

George, L. K., Larson, D. B., Koenig, H. O., \& McCullough, M. E. (2000). Spirituality and health: What we know, what we need to know. Journal of Social and Clinical Psychology, 19, 102-116.

Haque, A., \& Kamil, N. (2012) Islam, Muslims and mental health. In Ahmed, S., \& Amer, M. M. (Eds.), Counseling Muslims: Handbook of Mental Health Issues and Interventions (pp. 3-13). New York, NY: Routledge/Taylor \& Francis Group.

Inayat, Q. (2007). Islamophobia and the therapeutic dialogue: Some reflections. Counselling Psychology Quarterly, 20, 287-293.

Keshavarzi, H. \& Haque, A. (2013). Outlining a psychotherapy model for enhancing Muslim mental health within an Islamic context. The International Journal for the Psychology of Religion, 23, 230-249.

Kianpoor, M., \& Rhoades Jr., G. F. (2005). “Djinnati,” A possession state in Balochistan, Iran. Journal of Trauma Practice, 4, 147-155.

Koenig, H. G. (2001). Religion and medicine IV: Religion, physical health and clinical implications. International Journal of Psychiatry, 31, 321-336.

Lea, T., Richards, P., Sanders, P., McBride, J., \& Allen, G. (2015). Spiritual pathways to healing and recovery: An intensive single-n study of an eating disorder patient. Spirituality in Clinical Practice, 2(3), 191-201. doi:10.1037/scp0000085

McMinn, M. R., Aikins, D. C., \& Lish, R. A. (2003). Basic and advanced competence in collaborating with clergy. Professional Psychology Research and Practice, 34(2), 197-202. Doi: 10.1037/0735-7028.34.2.197

Mental Health Commission of Canada. (2018). Mental Health First Aid Canada: Courses. Retrieved from http://www.mentalhealthfirstaid.ca/en/course-info/ courses

Milstein, G., Manierre, A., Susman, V. L., \& Bruce, M. L. (2008). Implementation of a program to improve the continuity of mental health care through Clergy Outreach and Professional Engagement (C.O.P.E.). Professional Psychology: Research and Practice, 39, 218-228.

Milstein, G., Manierre, A., \& Yali, A. M. (2010). Psychological care for persons of diverse religions: A collaborative continuum. Professional Psychology: Research and Practice, 41, 371-381.

National Institute of Mental Health (2019). Mental Illness. Retrieved April 20, 2019, from https://www.nimh.nih.gov/health/statistics/mental-illness.shtml 
Nimer, M. (2002). The North American Muslim Resource Guide: Muslim Community Life in the United States and Canada. New York, NY: Routledge.

O'Conner, P. J., Pronk, N. P., Tand, A., \& Whitebird, R. P. (2005) Characteristics of adults who use prayer as an alternative therapy. American Journal of Health Promotion, 19, 369-375.

Pargament, K. I. (1997). The psychology of religion and coping. New York, NY: Guilford.

Pew Research Center. (2007). American Muslims [Data file]. Retrieved from http:// pewglobal.org/datasets/

Razali, S. M. (1999). Conversion disorder: A case report of treatment with the Main Puteri, a Malay shamanistic healing ceremony. European Psychiatry, 14, 470-472.

Richards, P., Sanders, P., Lea, T., McBride, J., \& Allen, G. (2015). Bringing spiritually oriented psychotherapies into the health care mainstream: A call for worldwide collaboration. Spirituality in Clinical Practice, 2(3), 169-179. doi:10.1037/scp0000082

Salib, E., \& Youakim, S. (2001). Spiritual healing in elderly psychiatric patients: A casecontrol study in an Egyptian psychiatric hospital. Aging \& Mental Health, 5, 366370.

Wang, P. S., Berglund, P. A., \& Kessler, R. C. (2003). Patterns and correlates of contacting clergy for mental disorders in the United States. Health Services Research, 38, 647-673.

World Health Organization. (2003). Investing in mental health. Geneva, Switzerland: WHO.

World Health Organization, War Trauma Foundation and World Vision International (2011). Psychological first aid: Guide for field workers. Geneva, Switzerland: WHO.

Worthington, E., Hook, J., Davis, D., \& McDaniel, M. (2011). Religion and spirituality. Journal of Clinical Psychology, 67(2), 204-214. doi:10.1002/jclp.20760 